Research, Society and Development, v. 9, n.1, e197911861, 2020

(CC BY 4.0) | ISSN 2525-3409 | DOI: http://dx.doi.org/10.33448/rsd-v9i1.1861

\title{
Exposições itinerantes e a popularização das Geociências
}

Traveling exhibitions and the popularization of geosciences

Exposiciones itinerantes y la popularización de las geociencias

Recebido: 14/10/2019 | Revisado: 22/10/2019 | Aceito: 29/10/2019 | Publicado: 31/10/2019

\section{Caiubi Emanuel Souza Kuhn}

ORCID: https://orcid.org/0000-0003-1434-9433

Universidade Estadual Paulista e Universidade Federal do Mato Grosso, Brasil

E-mail: caiubigeologia@ hotmail.com

Flávia Regina Pereira Santos de Siqueira

ORCID: https://orcid.org/0000-0002-8309-3948

Universidade Federal do Mato Grosso, Brasil

E-mail: frpsantos@ hotmail.com

Livia Halle Najm de Sá

ORCID: https://orcid.org/0000-0002-1819-8508

Universidade Federal do Mato Grosso, Brasil

E-mail: liviahalle@gmail.com

Gustavo Gomes Pereira

ORCID: https://orcid.org/0000-0001-9177-8472

Universidade Federal do Mato Grosso, Brasil

E-mail: gomes951@ @otmail.com

Lucas Rafael Delcico Rezende

ORCID: https://orcid.org/0000-0001-7489-3970

Universidade Federal do Mato Grosso, Brasil

E-mail: lucasdelcico@ hotmail.com

Daniel Souza Dias

ORCID: https://orcid.org/0000-0002-4400-0278

Universidade Federal do Mato Grosso, Brasil

E-mail: danieldiasgeologia@gmail.com

\section{Resumo}

Os conteúdos ligados às geociências são fundamentais para que o cidadão consiga realizar uma análise correta sobre o sistema da Terra, suas variáveis e limitações, permitindo assim 
que sejam tomadas decisões conscientes que garantam a sustentabilidade do nosso planeta. Atualmente, na educação básica, os conteúdos geocientíficos estão presentes em várias disciplinas como física, química, geografia e biologia. Esse trabalho possui como objetivo apresentar os resultados de uma abordagem multidisciplinar realizada por um projeto de extensão, por meio de exposições itinerantes de rochas, minerais, fósseis e materiais arqueológicos. As exposições foram realizadas em escolas e eventos situados na região metropolitana de Cuiabá, Estado de Mato Grosso. As ações foram desenvolvidas por meio do Projeto de Extensão Educação e Geociências, entre os anos de 2016 e 2018, e alcançaram de forma direta cerca de 5.487 pessoas. Desta forma, as exposições contribuíram para o processo de ensino e aprendizagem dos estudantes, e auxiliou no processo de popularização da ciência. A metodologia desenvolvida pode ser replicada em outros locais ou servir como referência para construção de ações similares.

Palavras-chave: Projeto de extensão, meio ambiente, sustentabilidade, sociedade.

\begin{abstract}
The contents linked to geosciences are fundamental for the citizen to be able to make a correct analysis of the Earth system, its variables and limitations, thus allowing conscious decisions to be made to guarantee the sustainability of our planet. Currently, in basic education, geoscientific contents are present in various disciplines such as physics, chemistry, geography and biology. This paper aims to present the results of a multidisciplinary approach performed by an extension project through itinerant exhibitions of rocks, minerals, fossils and archaeological materials. The exhibitions were held at schools and events located in the metropolitan region of Cuiabá, State of Mato Grosso, Brazil. The actions were developed through the Education and Geosciences Extension Project, between the years 2016 and 2018, and directly reached about 5,487 people. Thus, the exhibitions contributed to the process of teaching and learning of students and helped in the process of popularization of science. The developed methodology can be replicated elsewhere or be used as a reference for building similar actions.
\end{abstract}

Key-words: Extension project, environment, sustainability, society.

\title{
Resumen
}

Los contenidos vinculados a las geociencias son fundamentales para que el ciudadano pueda hacer un análisis correcto sobre el sistema de la Tierra, sus variables y limitaciones, lo que permite tomar decisiones conscientes para garantizar la sostenibilidad de nuestro planeta. 
Actualmente, en educación básica, los contenidos geocientíficos están presentes en diversas disciplinas como la física, la química, la geografía y la biología. Este documento tiene como objetivo presentar los resultados de un enfoque multidisciplinario llevado a cabo por un proyecto de extensión a través de exposiciones itinerantes de rocas, minerales, fósiles y materiales arqueológicos. Las exposiciones se llevaron a cabo en escuelas y eventos ubicados en la región metropolitana de Cuiabá, estado de Mato Grosso. Las acciones se desarrollaron a través del Proyecto de Extensión de Educación y Geociencias, entre 2016 y 2018, y llegaron directamente a unas 5,487 personas. Por lo tanto, las exposiciones contribuyeron al proceso de enseñanza y aprendizaje de los estudiantes y ayudaron en el proceso de popularización de la ciencia. La metodología desarrollada podrá replicarse en otro lugar o servir como referência para construir acciones similares.

Palabras clave: Proyecto de extensión, medio ambiente, sostenibilidad, sociedad.

\section{Introdução}

Os Objetivos do Desenvolvimento Sustentável (ODS) são um conjunto de esforços internacionais pela construção de ações globais, que assegurem que a sociedade caminhe para níveis de consumo e práticas, que garantam a sustentabilidade do planeta. A educação possui um papel essencial para que isso ocorra, pois através dela é possível formar cidadãos que consigam tomar decisões conscientes, ponderando diversos aspectos ambientais e sociais relacionados aos hábitos da sociedade. Entre os objetivos previstos para educação, a meta 4.7 dos ODS, estabelece que:

“Até 2030, garantir que todos os alunos adquiram conhecimentos e habilidades necessárias para promover o desenvolvimento sustentável, inclusive, entre outros, por meio da educação para o desenvolvimento sustentável e estilos de vida sustentáveis, direitos humanos, igualdade de gênero, promoção de uma cultura de paz e da não violência, cidadania global e valorização da diversidade cultural e da contribuição da cultura para o desenvolvimento sustentável” (Onu, 2019).

O Brasil ainda precisa avançar muito na área educacional, inclusive em relação ao ensino de ciências. Conforme dados do Programme for International Student Assessment (PISA), o desempenho dos estudantes brasileiros em Ciência avançou pouco nas últimas décadas, passando de 390 pontos em 2006 para 401 pontos em 2015. Este valor ficou bem 
abaixo da média dos países da Organização para a Cooperação e Desenvolvimento Econômico (OCDE) que foi de 493 pontos (Pisa, 2019).

Os conteúdos relacionados as geociências estão entre os conhecimentos essenciais para possibilitar uma análise correta do planeta Terra e suas limitações. Conforme Silva (2018) esta área do conhecimento permite compreender o planeta como um sistema complexo, sujeito a diversas transformações, das quais somos parte integrante e dependente. Tais informações auxiliam na tomada de decisões políticas, econômicas e socioambientais.

Reconhecer os limites relacionados ao meio físico ou biológico da natureza, cria possibilidades para visualizar onde estamos posicionados, identificando faltas ou excessos, para desta forma estabelecer direções a serem tomadas para reduzir impactos de maneira igualitária, considerando as dimensões ética e social (Cidin \& Silva, 2004).

O crescimento populacional, as mudanças climáticas e a ampliação do padrão de consumo, se apresentam como grandes desafios para o século XXI. Temas como gestão de recursos naturais, ordenamento territorial, acesso a água potável, destinação de resíduos sólidos, desastres naturais, serviços ecossistêmicos e conservação do solo, entre outros tópicos, vão ser arduamente debatidos nas próximas décadas e precisam ser compreendidos pela população em geral.

Uma abordagem educacional integrada, que considere a complexidade dos sistemas terrestres e sua relação com as questões sociais e ambientais, é a melhor forma para facilitar o processo de ensino-aprendizagem, permitindo a formação de cidadãos conscientes dos desafios existentes para humanidade (Silva, 2018; Guimarães, 2004).

Os conteúdos geocientíficos no ensino médio no Brasil, estão disseminados em disciplinas como Física, Química, Biologia e Geografia (Kuchenbecker, 2017). Em relação ao ensino infantil, embora não esteja presente no currículo, a divulgação de conhecimentos relacionados a geologia nas séries iniciais pode aguçar a curiosidade pelos objetos da ciência. Para Ruchkys et al., (2012) a apresentação de temas ligados a geologia para crianças, pode construir uma possibilidade de maior entendimento e aproximação do homem com recursos naturais.

Um dos fatores que dificulta o ensino de temas geológicos, é que muitos dos exemplos apresentados em livros e materiais didáticos nas escolas, são ilustrações globais, que são importantes, mas, nem sempre trazem a contribuição que o professor deseja ou necessita 
(Almeida et al., 2015). Os exemplos regionais em alguns casos poderiam ser assimilados pelos estudantes de forma muito mais fácil.

O contato com o objeto científico também é importante na formação dos estudantes, mas no Brasil, ferramentas como os acervos museológicos, em geral, ainda estão muito restritas aos grandes centros (Kuhn, 2016). E mesmo nestes locais, as escolas periféricas possuem dificuldades de acesso aos acervos, uma vez que os recursos são restritos, fato que dificulta a locomoção de estudantes e professores até as instituições museológicas. A realização de exposições itinerantes é uma forma de permitir acesso a conteúdo ligados as geociências, para auxiliar na formação dos estudantes e fomentar a popularização da ciência.

Nas universidades a extensão universitária reúne, estimula, incentiva, apoia e propõe projetos e ações, como instrumentos efetivos de mudança da Universidade e da sociedade, para assim enfrentar os desafios relacionados ao cenário social e as oportunidades que se descortinam no contexto internacional e na realidade brasileira (Proex, 2012; Ufmt, 2014).

O projeto realizou, entre os anos de 2016 e 2018, exposições itinerantes com informações sobre o tempo geológico, dinâmica de processos superficiais, recursos hídricos e recursos minerais. Este trabalho possui como objetivo apresentar a dinâmica utilizada e os resultados do projeto Educação e Geociências.

\section{Materiais e métodos}

O trabalho utilizou metodologia ativa (Pereira et al., 2018), onde foi realizado o preparo de amostras e materiais em gabinete e laboratório; a sistematização de dados bibliográficos para confecção dos banners e materiais didáticos; e por fim, o desenvolvimento e apresentação de dinâmicas nas escolas selecionadas.

A análise dos dados foi realizada de forma quantitativa para o número de pessoas alcançadas pela ação. Foi realizada uma análise empírica para fatores como aceitação da proposta e impacto indireto, com base em informações orais e dados disponíveis em relatórios, ou em notícias veiculadas na rede mundial de computadores.

O acervo itinerante foi composto por materiais arqueológicos, fósseis, rochas, minerais e banners. O Quadro 1, apresenta alguns dos materiais utilizados no projeto. As amostras de minerais e rochas foram cedidas pelo Museu de Rochas, Minerais e Fósseis da Faculdade de Geociências (FAGEO) da Universidade Federal de Mato Grosso (UFMT). As 
amostras de fósseis e artefatos arqueológicos foram cedidas pelo Museu de História Natural Casa Dom Aquino em Cuiabá (MT).

Quadro 1: Materiais usados nas exposições itinerantes do projeto Educação e Geociências.

\begin{tabular}{|l|l|}
\hline Material & Descrição \\
\hline $\begin{array}{l}\text { Rochas e } \\
\text { minerais }\end{array}$ & $\begin{array}{l}\text { Rochas sedimentares, ígneas e metamórficas, além de minerais como } \\
\text { magnetita ou hematita, galena, azurita ou malaquita, cromita, } \\
\text { magnesita, quartzo, esfarelita, cassiterita, apatita e lepdolita. }\end{array}$ \\
\hline Fósseis & $\begin{array}{l}\text { Braquiópodes, tentaculites, trilobita, um dente de eremotherium } \\
\text { (preguiça gigante), um dente de mastodonte, um estromatólito, } \\
\text { vertebra de dinossauro herbívoro (Saurópode e/ou terópode) e um } \\
\text { dente de carnívoro (terópode). }\end{array}$ \\
\hline $\begin{array}{l}\text { Artefatos } \\
\text { arqueológicos }\end{array}$ & $\begin{array}{l}\text { Louças do século XIX, cerâmicas indígenas e afro-brasileira, } \\
\text { utensílios de ferro e cobre da época dos escravos como colheres e } \\
\text { tornozeleiras, além de ferramentas de pedra lascada e pedra polida. }\end{array}$ \\
\hline Banners & $\begin{array}{l}\text { Foram confeccionados pelo projeto banners para serem usados para } \\
\text { ilustrar as apresentações. }\end{array}$ \\
\hline
\end{tabular}

Fonte: Relatórios do Projeto Educação e Geociências.

A diversidade dos materiais utilizados facilita despertar o interesse dos estudantes, assim como, possibilita abordar diferentes conteúdos didáticos.

Os banners foram confeccionados pela equipe dos projetos e são relacionados à diversos temas das geociências, tais como, história da vida na Terra, erosão, ciclo hidrológico, importância dos minerais de rochas no dia a dia, origem da Terra, entre outros. Para cada uma das temáticas abordadas nas exposições itinerantes foi elaborado uma dinâmica de apresentação visando facilitar a aprendizagem do aluno.

As exposições foram realizadas por monitores capacitados pelo projeto, que explicavam o conteúdo aos estudantes das escolas atendidas sobre diferentes temáticas de acordo com a demanda apresentada pela escola. $\mathrm{O}$ agendamento foi realizado por meio de contato da equipe do projeto com escolas locais, ou por via inversa. Para preencher a agenda anual o projeto utilizava como estratégia a divulgação das ações. A divulgação foi feita através de realizes direcionados para os grandes meios de comunicação local, como jornais, sites e redes de televisão; além da divulgação em redes sociais na internet.

No ano de 2016 o Projeto Educação e Geociências abordou as temáticas: tempo geológico e o uso dos recursos minerais. Em 2017 foram adicionados os temas aquíferos, processos de dinâmicas superficiais e geociências e comunidades indígenas. Devido ao sucesso da proposta em 2018 surgiu o Programa de Extensão Educação, Geociências e 
(CC BY 4.0) | ISSN 2525-3409 | DOI: http://dx.doi.org/10.33448/rsd-v9i1.1861

Mineração, composto por cinco projetos. Dentre eles, permaneceu o Projeto "Educação e Geociências" e surgiu o Projeto "Mineração e o Consumo de Bens Minerais", ambos com enfoque para desenvolvimento de exposições itinerantes sobre geociências e mineração, respectivamente. Além destes dois projetos o programa de extensão também foi composto pelos projetos "Geociências e Comunidades Indígenas", "Qualificação Continuada em Geociências" e pelo "Projeto Geociências e Jogos Digitais".

Assim, a partir de 2018 as escolas atendidas passaram a receber os dois projetos que utilizam de exposições itinerantes em conjunto. O que resultou no aumento da quantidade de conteúdo em consequência disto as ações passaram a atender menos turmas por escolas em uma única exposição. A Figura 1 ilustra alguns dos materiais itinerantes.

Figura 1: Imagens dos materiais utilizados nas exposições itinerantes. 1) Rocha sedimentar: arenito com estratificação cruzada; 2) Rocha ígnea: granito; 3) Rocha metamórfica: granada micaxisto; 4) louça do século XIX; 5) ponta de lança feita de silexito; 6) cerâmica indígena; 7) vertebra de terópode (dinossauro); 8) dente eremotherium (preguiça gigante); 9) dente de mastodonte.
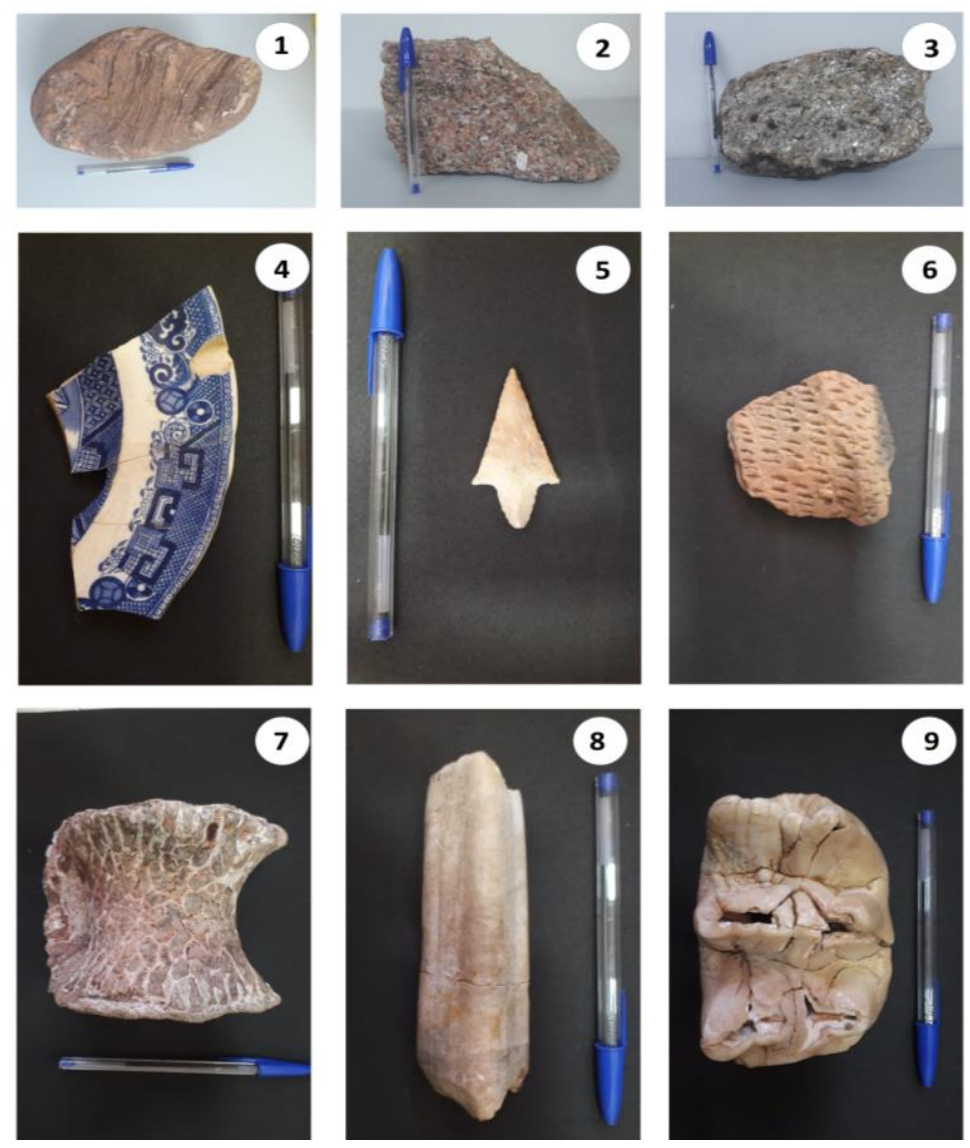

Fonte: Acervo fotográfico do Projeto Educação e Geociências. 
Os fósseis de dinossauro, preguiça gigante entre outros, podem ser facilmente relacionados com filmes e documentários e com isso fica mais fácil criar uma concepção sobre os conteúdos abordados. Por outro lado, artefatos arqueológicos facilitam discutir o vínculo entre extração mineral e desenvolvimento social.

Após a realização da exposição a equipe elaborava um relatório sintético com as informações básicas sobre o público atendido. Ao final de cada ano o projeto apresentou para a Coordenação de Extensão da Universidade Federal de Mato Grosso (UFMT) um relatório completo com as ações do projeto.

\section{Resultados}

\subsection{Roteiro didático das exposições}

A seguir são apresentados resumos dos roteiros didáticos utilizados nas exposições itinerantes. Os temas tratados foram: tempo geológico, rochas, minerais, mineração, ciclo hídrico e solos e processos de dinâmica superficial.

A abordagem sobre o tempo geológico conduzia os estudantes a uma viagem pelo história da Terra. Desde o surgimento do universo e do sistema solar, passando pelos Eons Hadeano, Arqueano, Proterozóico e Fanerozóico. Este último Eon foi apresentado com mais detalhe, através dos principais fatos que ocorreram nas Eras Paleozoica, Mesozoica e Cenozoica. Eventos como surgimento de espécies, grandes extinções, glaciações e a dança dos continentes em cada Período geológico através das reconstituições paleogeográficas.

As amostras de fósseis se mostraram uma ferramenta que facilita o processo de aprendizagem e aumenta o interesse dos discentes. Por fim, a apresentação sobre a origem do homem no Cenozoico, abria espaço para abordar sobre os artefatos arqueológicos. Desta forma, iniciar o debate sobre a utilização das rochas e minerais no nosso dia a dia, desde o paleolítico até a sociedade tecnológica atual.

Nesta etapa conceitos sobre sustentabilidade e sobre a relação entre a sociedade moderna e a mineração eram debatidos com estudantes, para demonstrar que itens como o celular, possuem como matéria prima dezenas de minerais e que praticamente tudo que utilizamos vem da mineração.

Por isso, ressaltava-se que cada pessoa precisa fazer a sua parte para que se consiga utilizar os recursos naturais com a maior eficiência possível, em especial os recursos não 
renováveis. A destinação dos resíduos gerados pela sociedade devem ser uma preocupação de todos, como por exemplo, o lixo eletrônico que é composto por diversos bens minerais e geralmente é descartado de maneira incorreta. Caso esse material seja descartado de forma errada, além de ser um desperdício de recursos minerais, também pode gerar a contaminação do meio ambiente.

$\mathrm{Na}$ abordagem sobre ciclo hidrológico foi trabalhado desde a origem da água e dos primeiros mares no planeta Terra, até a distribuição atual entre os diferentes tipos de reservatórios, como oceanos, aquíferos, geleiras, atmosfera e biosfera. Um dos banners demonstra o ciclo longo e o ciclo curto da água, trazendo assim uma dimensão mais ampla sobre esse recurso natural. Informações sobre os diferentes tipos de aquíferos eram repassadas para o público, através de exemplos regionais de aquíferos poros e fraturados, vinculados a formação Botucatu (Aquífero do Guarani) e Grupo Cuiabá, respectivamente.

Para facilitar o entendimento sobre o que é um aquífero foi realizada a experiência de despejar um pouco de água sobre a amostra de arenito. Com isto os estudantes podiam observar o processo de infiltração da água na rocha e assim, demonstrando que os arenitos se comportam como grandes "esponjas" que armazenam as águas das chuvas. Era explicado que a água das nascentes é na verdade, a mesma água que estava armazenada no meio das rochas do subsolo.

O desenvolvimento do solo e os processos de dinâmica superficial, eram trabalhados através da abordagem sobre a formação de ravinas e boçorocas, corrida de detritos, rastejo, deslizamento e queda de blocos. Este tema abria um debate sobre a importância do planejamento territorial e da conservação do solo.

\subsection{Quantitativo das exposições}

Ao longo de três anos, as exposições atenderam cerca de 5.487 pessoas, no decorrer de 21 exposições, realizadas em três municípios diferentes (Quadro 2).

O público principal foi de estudantes do $6^{\circ}$ ano do ensino fundamental até a terceira série do ensino médio. Contudo também foram realizadas exposições para discentes das séries iniciais do ensino básico, para adolescentes e instituições de ensino de jovens e adultos (EJA), além de pessoas de diversos segmentos alcançadas através dos eventos atendidos pelo projeto (Figura 2). 
Research, Society and Development, v. 9, n.1, e197911861, 2020

(CC BY 4.0) | ISSN 2525-3409 | DOI: http://dx.doi.org/10.33448/rsd-v9i1.1861

Quadro 2 - Escolas e eventos atendidos, municípios no qual a exposição foi realizada e números de pessoas diretamente alcançadas por ano.

\begin{tabular}{|c|c|c|c|}
\hline Ano & Unidade Escolar / Evento & Cidade & $\begin{array}{l}\text { Público } \\
\text { estimado }\end{array}$ \\
\hline \multirow{4}{*}{2016} & E.E. Fernando Leite de Campos & Várzea Grande & \multirow{4}{*}{2.500} \\
\hline & $\begin{array}{l}\text { Instituto Federal de Mato Grosso } \\
\text { (IFMT) }\end{array}$ & Cuiabá & \\
\hline & E.E. Rafael de Siqueira & Chapada dos Guimarães & \\
\hline & II SENG - Campus Várzea Grande & Cuiabá & \\
\hline \multirow{6}{*}{2017} & E.E. José Garcia Neto & Várzea Grande & \multirow{6}{*}{1.050} \\
\hline & E.E. Francisco A. Ferreira Mendes & Cuiabá & \\
\hline & III SENG - Campus Várzea Grande & Cuiabá & \\
\hline & E.E. Raimundo Pinheiro da Silva & Cuiabá & \\
\hline & E.E. José Leite de Moraes & Várzea Grande & \\
\hline & E.E. Antônio Epaminondas & Cuiabá & \\
\hline \multirow{11}{*}{2018} & E.E. Tancredo A. Neves & Cuiabá & \multirow{11}{*}{1.937} \\
\hline & E.E. Professora Eliane Digigov & Cuiabá & \\
\hline & E.E. Mariana Luiza Moreira & Cuiabá & \\
\hline & E.E. Agenor Ferreira Leão & Cuiabá & \\
\hline & E.E. José Garcia Neto & Várzea Grande & \\
\hline & E.E. Senador Azeredo & Cuiabá & \\
\hline & E.E. Salim Felício & Cuiabá & \\
\hline & E.E. Juarez Rodrigues dos Anjos & Cuiabá & \\
\hline & $\begin{array}{l}\text { Workshop Geoparque de Chapada } \\
\text { dos Guimarães }\end{array}$ & Chapada dos Guimarães & \\
\hline & E. E. São Jose & Chapada dos Guimarães & \\
\hline & E. M. Santa Helena* & Chapada dos Guimarães & \\
\hline \multicolumn{3}{|c|}{$\begin{array}{l}\text { Público total estimado } \\
\end{array}$} & 5.487 \\
\hline
\end{tabular}

Fonte: Relatórios do Projeto Educação e Geociências.

As ações foram muito bem recebidas pela comunidade e tiveram uma demanda crescente ao longo dos anos. Entretanto, a falta de recursos financeiros para financiar as atividades do projeto foi o fator limitante para atendimento das solicitações realizadas pelas escolas. A mídia local demonstrou possuir grande interesse nas temáticas abordadas nas exposições. Ao logo dos anos foram realizadas diversas reportagens em jornais e televisão, demonstrando o trabalho realizado pela equipe (Figura 3). 
Figura 2: Registro fotográfico das exposições itinerantes, onde é possível observar o público de diferentes faixas etárias interagindo com o acervo e monitores.
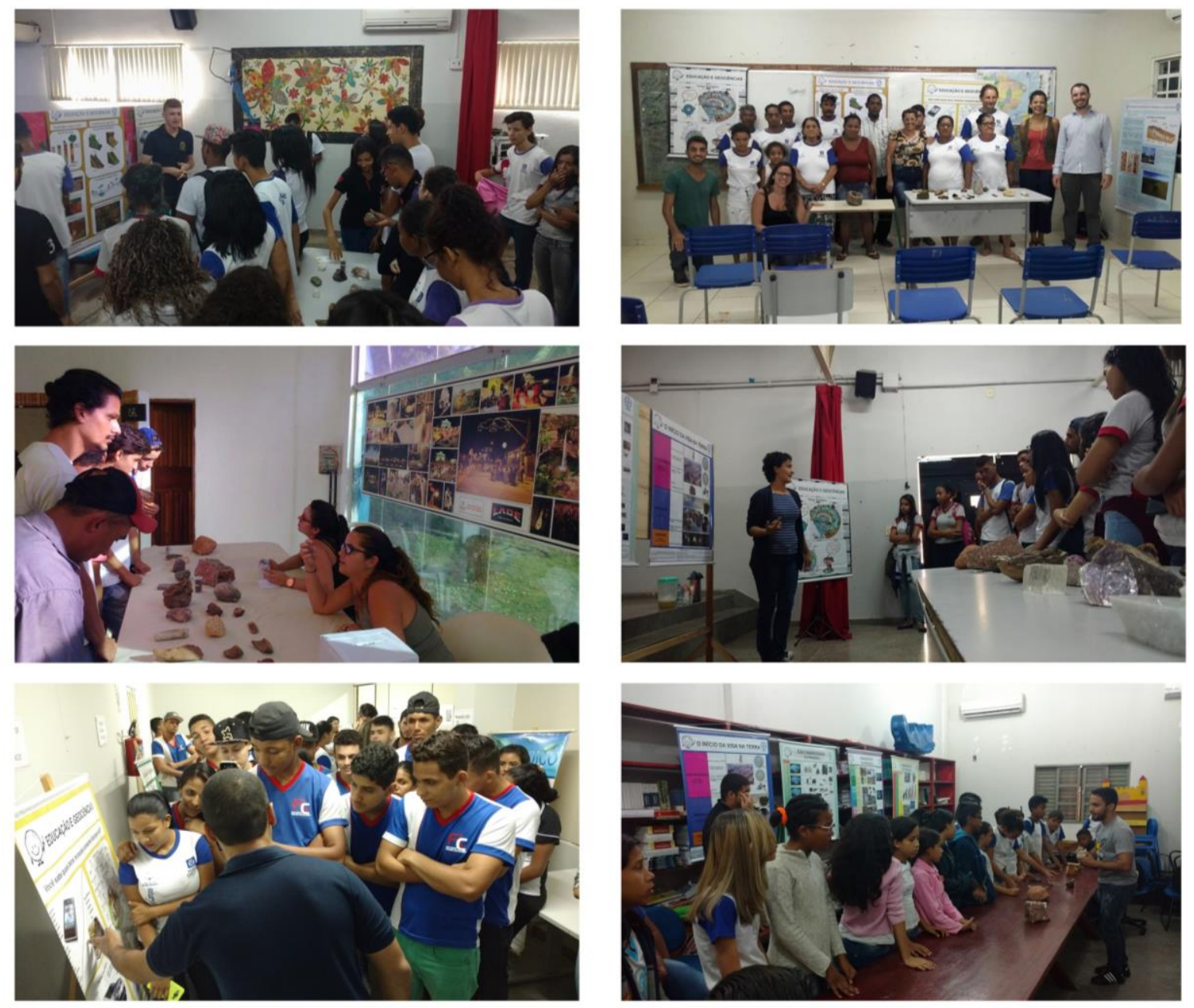

Fonte: Acervo fotográfico do Projeto Educação e Geociências.

A divulgação nos veículos de comunicação por si só é um resultado expressivo, pois apresenta para sociedade informações locais relevantes sobre arqueologia, geologia, paleontologia, ciclo da água e sustentabilidade, alcançando diversos públicos distintos por meio das reportagens temáticas produzidas. Esse trabalho ajuda também a fortalecer as instituições museológicas parceiras. Desta forma a divulgação na mídia foi também uma forma de realizar a popularização do conhecimento científico.

As figuras 3, 4 e 5 mostram diferentes dimensões do impacto do projeto, com envolvimento desde diferentes públicos no decorrer da ação, até mesmo a abertura existente nos veículos de comunicação para divulgar conteúdos geocientíficos. 
Research, Society and Development, v. 9, n.1, e197911861, 2020

(CC BY 4.0) | ISSN 2525-3409 | DOI: http://dx.doi.org/10.33448/rsd-v9i1.1861

Os meios de comunicação utilizados foram a página no facebook do projeto e reportagens através de redes TV aberta (Figura 4). Neste meio, além de informações sobre as exposições itinerantes, são compartilhados conteúdos didáticos ligados aos temas dos projetos, visando incentivar professores e alunos a se aprofundarem em tópicos ligados as geociências e o uso de recursos minerais.

Figura 3: Notícias veiculadas em sites de notícias sobre as atividades do projeto.

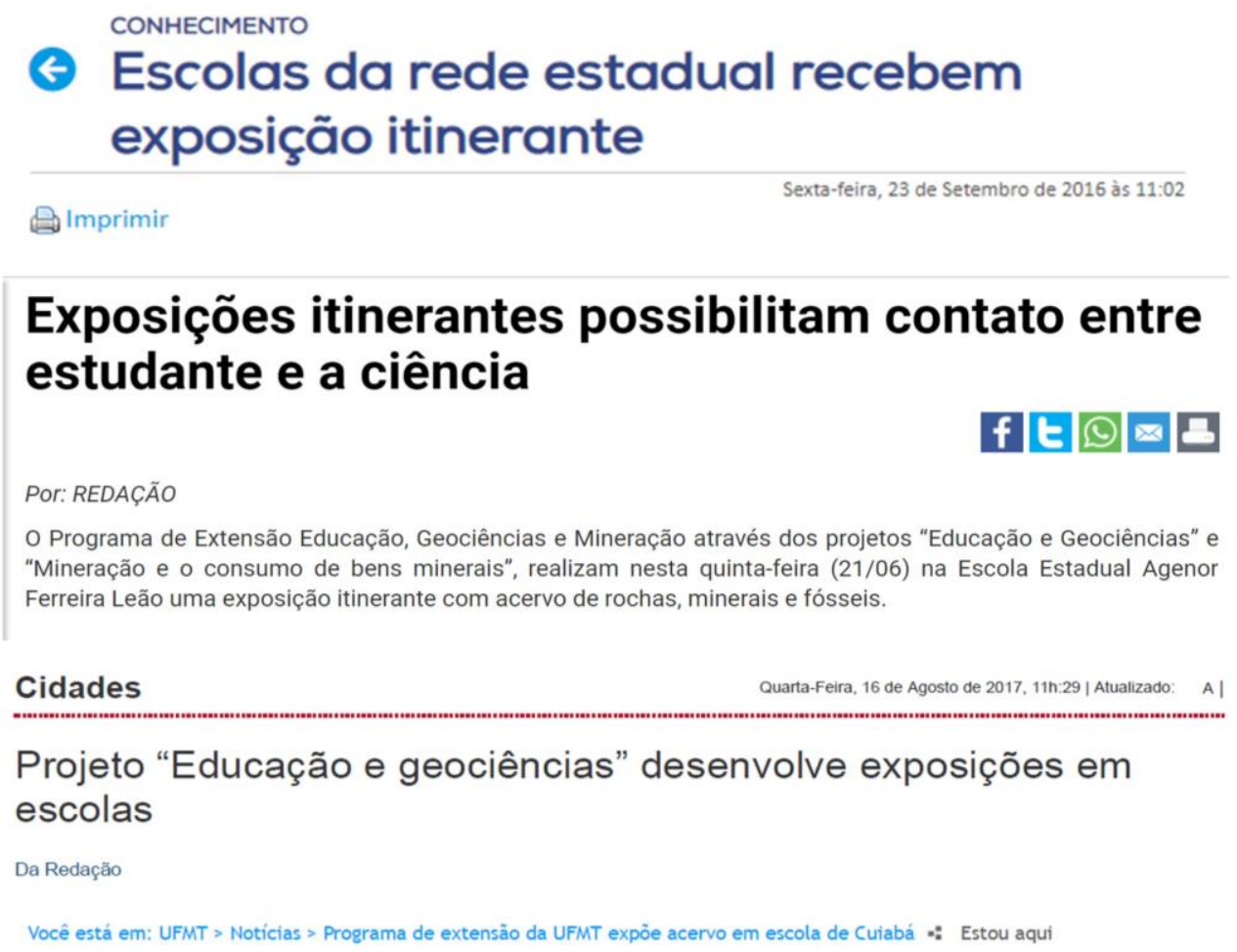

\section{Programa de extensão da UFMT expõe acervo em escola de Cuiábá}

Publicado em Noticias | 19/06/2018

Fonte: Reportagens publicadas por SEDUC (2016), UFMT (2018), Hipernotícias (2018), Crea-MT (2017) e UFMT (2017).

\section{Discussões}

A abordagem multidisciplinar envolvendo conceitos de química, física, biologia e geografia, auxilia no desenvolvimento de uma visão crítica construída através de uma abordagem integrada sobre conteúdos educacionais. Para os monitores do projeto, as exposições foram uma oportunidade de aprimorarem seu conhecimento e adquirem prática na apresentação de conteúdos científicos para sociedade. Em pesquisa realizada com os membros 
(CC BY 4.0) | ISSN 2525-3409 | DOI: http://dx.doi.org/10.33448/rsd-v9i1.1861

da equipe do projeto, foi constatada a importância da ação na formação acadêmica de cada um deles (Kuhn et al., 2019)

Figura 4: Vídeos das reportagens realizadas por redes de televisão sobre as exposições itinerantes.

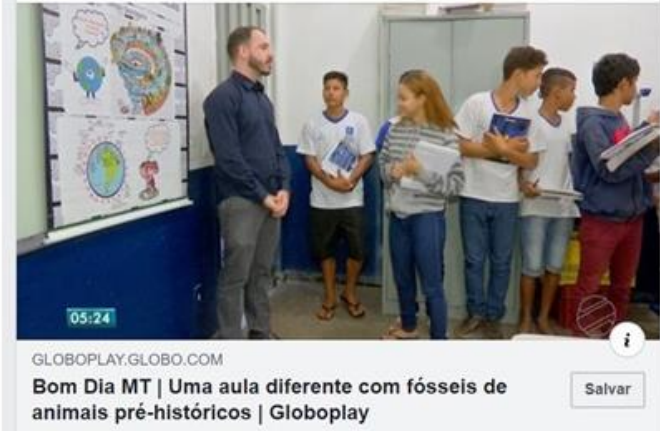

animais pré-históricos | Globoplay

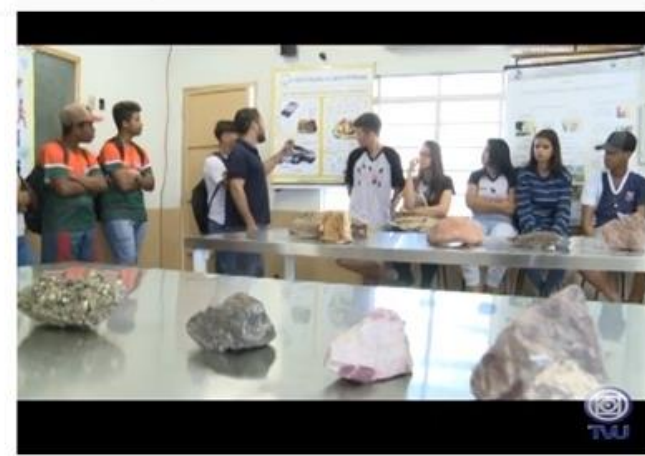

Projeto de Educação em Geociência

264

(9.2) TV Universidade - UFMT

Publicado em 12 de set de 2017

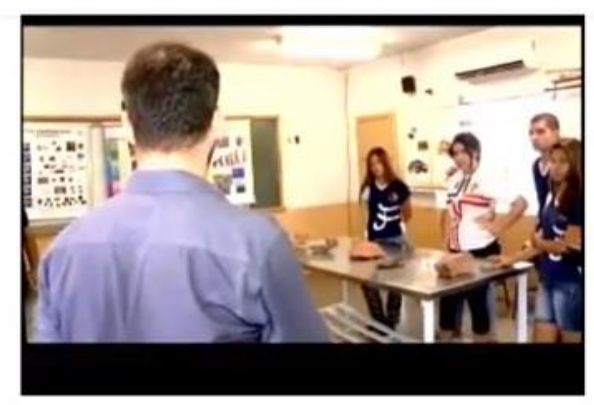

Projeto Geociência faz sucesso em escolas da Capital

87 If 5 \% 10 क COMPARTILHAR ${ }_{+}$SALVAR $\ldots$

TV VILA REAL CANAL 10 CUIABÁ

Publicado em 18 de ago de 2017

INSCREVER-SE 78 MIL.

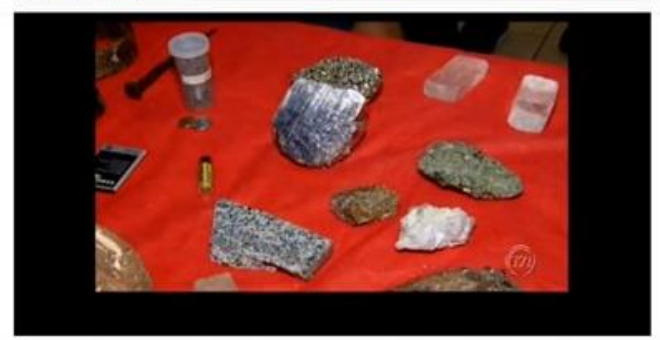

Alunos da UFMT passam conhecimentos para estudantes de escola

169 visualizaçbes $1.7 \%$ \% COMPARTILHAR 10 SALVAR ...

TV VILA REAL CANAL 10 CUIABÁ
Publicodo em 22 de ILI de 2018

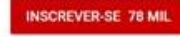

Fonte: Reportagens divulgadas em canais de TV aberta, tais como, Globo (2018), Gazeta Digital (2017), Gazeta Digital (2018) e TV Universidade (2017)

A abordagem sobre o tempo geológico através dos fósseis, permite contar sobre às grandes extinções e os eventos extremos registrados na história da terra, tais como mudanças climáticas e impactos de meteoritos. Para Reis et al. (2005) a paleontologia auxilia a compreender aspectos geológicos, biológicos e ambientais, entretanto existe a necessidade de recursos didáticos que auxiliem na divulgação e no interesse do aluno do ensino fundamental e médio. As exposições itinerantes possibilitam o contato entre os estudantes e os fósseis, e desta forma, desmistifica e torna real os objetos de ciência que até então os estudantes viram apenas em livros, vídeos ou documentários. 
As dimensões do tempo geológico na casa dos milhares, milhões ou até bilhões de anos, facilitam os estudantes a enxergarem as diferentes escalas dos processos que ocorrem no nosso planeta. Com isso, também se torna mais fácil debater sobre as mudanças causadas pelo homem nas últimas décadas ou séculos. Uma vez que algumas alterações realizadas embora sejam comuns, estão ocorrendo em ritmo muito mais acelerado, como é o caso dos processos erosivos.

O estudo de ciências naturais, entre elas as geociências, utilizando de aulas tradicionais não contextualizadas e sem interação direta com fenômenos naturais ou tecnológicos deixam uma lacuna na formação dos estudantes (Ruchkys et al., 2012). No processo de aprendizagem novas ideias, é necessário que os conceitos mais relevantes estejam claros na estrutura cognitiva, ancorando novas ideias e conceitos (Almeida et al., 2015). Desta forma aproximar objetos de estudos e estudantes facilita a assimilação dos conteúdos.

O homem utiliza os recursos minerais desde a pré-história como jaspe, quartzo, calcedônia para a confecção de ferramentas rudimentares, que eram usados para fabricar machados, pontas de flechas, mãos de pilão, facas, furadores, raspadores e outros (Vaz \& Carneiro 2016). Para se fabricar uma computados são usados AG, AU, CD, CU, FE, K, MN, NA, NI ZN, PB, SI, AS, CA, SB, SE, SN (Ferreira \& Ferreira 2008), todos esses elementos vêm dos minerais.

Os minerais são recursos não renováveis, assim como o petróleo e o gás natural. Em ambos os casos, eles são usados para trazerem conforto e praticidade ao nosso dia a dia. A fabricação de produtos como roupas, colchões, embalagens para alimentos e medicamentos, brinquedos, móveis e eletrodomésticos, carros, aviões, xampus e cosméticos necessita de insumos que vem da mineração e/ou da indústria de petróleo e gás (Silva, 2018).

A quantidade de insumos extraídos para que sejam fabricados itens para o nosso dia a dia, depende diretamente dos padrões de consumo e da destinação de resíduos dada pela sociedade para cada item descartado. Sendo assim, as escolas devem debater sobre lixo tecnológico e seu potencial de reciclagem (Kuhn et al., 2016). Para Ferreira \& Ferreira (2008) independente da visão do ser humano sobre a forma de reciclagem, seja relacionada, visando desafio ou oportunidade de lucro, é preciso que seja construída uma conscientização, seguida de mudanças de hábitos em relação a toda a cadeia de fabricação, aquisição e descarte de aparelhos eletroeletrônicos. 
Research, Society and Development, v. 9, n.1, e197911861, 2020

(CC BY 4.0) | ISSN 2525-3409 | DOI: http://dx.doi.org/10.33448/rsd-v9i1.1861

Conforme propõem Almeida \& Junior (2012), a geologia é uma ciência construída a partir da integração de conceitos provenientes de diversas áreas do saber, e o conhecimento de seus fundamentos, facilita que os estudantes tenham uma visão interdisciplinaridade na construção do pensamento científico relacionado a conteúdos de biologia, geografia, química, física e história.

Os diferentes períodos da história da humanidade estão diretamente relacionados com o domínio dos bens minerais, como por exemplo, idade da pedra lascada, idade da pedra polida, idade do bronze, entre outras. Por outro lado, o entendimento de processos relacionados a utilização dos minerais requer a compreensão de fundamentos físicos e químicos. Já a distribuição dos depósitos minerais ao redor do mundo é uma forma de debater desde placas tectônicas, paleogeografia e até geopolítica.

Para Bonito \& Morgado (2017), os professores devem romper com paradigmas eminentemente teóricos e passar a usar contributos da psicologia cognitiva. Por exemplo, através de metodologias ativas, participativas, que envolvam problemáticas locais e globais e a reflexão, para fomentar debates sobre possíveis soluções de diversos temas com a sociedade. As exposições itinerantes, neste contexto, podem facilitar a construção desta dinâmica interativa que busque formar perguntas e questionamentos na cabeça dos estudantes, e ao mesmo tempo, permitir compreender o meio em que vivem.

Silva (2018) defende a necessidade de promover a alfabetização em ciências da Terra, para que as pessoas possam compreender que o planeta em que vivemos e que extraímos os recursos, está em constantes mudanças. A autora argumenta que para avançar no sistema de ensino, é preciso formar quadros de professores que possam abordar de forma adequada os conteúdos, além de desenvolver recursos didáticos e práticas pedagógicas para as diferentes faixas etárias.

A sustentabilidade está relacionada com a forma como se compreende o planeta Terra e nas decisões realizadas após esse entendimento. Isto compreende o acesso à informação, conhecimento, reflexão, diálogo, discussão, elaboração do pensamento e olhar crítico para novas formas de pensar e hábitos que sejam possíveis (Silva, 2018). As atividades desenvolvidas pelo projeto abrem caminho para inúmeras reflexões sobre o planeta, o desenvolvimento da vida e as ações humanas, fomentando a construção de um pensamento crítico nos estudantes atendidos pelo projeto. 


\section{Considerações Finais}

As exposições itinerantes e a divulgação das ações através da mídia possibilitam a propagação do conhecimento científico.

O acesso a acervos e conteúdos didáticos sobre a história geológica da Terra, ligados ao contexto regional dos estudantes, facilita a abordagem e compreensão dos temas trabalhos no projeto.

O baixo custo das ações de popularização da ciência permite que sejam levadas até diversas escolas onde, no geral, os estudantes nunca tinham tido contato com conteúdo museológico.

Por outro lado, a falta de editais específicos e políticas próprias de fomento a ações de extensão impedem que projetos como o descrito neste artigo, consigam de se manter em atividade e expandir sua atuação.

Com base no exposto, este trabalho sugere que sejam ampliadas as temáticas e metodologias relacionadas com exposições itinerantes, para desta forma, aprimorar metodologias que fomentem a divulgação da ciência e o fortalecimento do ensino das geociências de forma multidisciplinar com outros conhecimentos de física, química, história, biologia entre outras disciplinas.

\section{Agradecimentos}

A Coordenação de Extensão (CODEX) da Universidade Federal de Mato Grosso, pelas bolsas concedidas aos monitores do projeto. Ao Museu de História Natural Casa Dom Aquino, Museu de Rochas Minerais da Faculdade de Geociências da UFMT (FAGEO) e ao Instituto Ecossistemas e Populações Tradicionais (ECOSS) pelo apoio ao projeto. Aos voluntários e bolsistas que participaram das atividades ao longo dos três anos.

\section{Referências}

Almeida C.N., Araújo C. \& Mello E.F. (2015). Geologia nas Escolas de Ensino Básico: a experiência do Departamento de Geologia da Universidade Federal do Rio de Janeiro. Terr a Didática, 11(3):150-161.Disponivel em: http://www.ige.unicamp.br/terraedidatica/. Acesso em: 27 de junho 2019. 
Bonito J. \& Morgado M. (2017). As Ciências da Terra na disciplina de Ciências Naturais do ensino básico em Portugal. In Terrae Didatica, 13(3):258-270. Disponível em: <http://www.ige.unicamp.br/terraedidatica/>. Acesso em: 27 de junho 2019.

Cidin, R.C.P.J. \& Silva, R.S. (2004). Pegada Ecológica: instrumento de avaliação dos impactos antrópicos do meio natural. Estudos Geográficos 2(1):43-52.

CREA-MT (2017, agosto 16). Projeto "Educação e geociências" desenvolve exposições em escolas. https://www.crea-mt.org.br/portal/clipping/projeto-educacao-e-geocienciasdesenvolve-exposicoes-em-escolas/

Ferreira J.M.de B., Ferreira A.C. (2008). A sociedade da informação e o desafio da sucata eletrônica; Revista de Ciências Exatas e Tecnologia, 3(3).

Gazeta Digital (2017). Projeto Geociência faz sucesso em escolas da Capital. [Arquivo de vídeo]. Recuperado de https://www.gazetadigital.com.br/video/36449

Gazeta Digital (2018). Alunos da UFMT passam conhecimentos para estudantes de escola. [Arquivo de vídeo]. Recuperado de https://www.gazetadigital.com.br/video/39626

Guimarães E.M. (2004). A contribuição da geologia na construção de um padrão de referência do mundo físico na educação básica; Revista Brasileira de Geociências. 34(1):87-94.

Globo. Bom dia - MT (2018, agosto 22) Uma aula diferente com fósseis de animais préhistóricos. [Arquivo de vídeo]. Recuperado de https://globoplay.globo.com/v/6963296/

Hipernotícias (2018, junho 20). Exposições itinerantes possibilitam contato entre estudante e a ciência. https://www.hipernoticias.com.br/cidades/exposicoes-itinerantes-possibilitamcontato-entre-estudante-e-a-ciencia/100324

Kuchenbecker M. (2017). Práticas multidisciplinares para o ensino introdutório de Geociências. In: Terra Didática, 13(3):303-309. Disponível em: <http://www.ige.unicamp.br/terraedidatica/>. Acesso em: 27 de junho 2019. 
Kuhn C.E. S. (2016). Ensino de geociências: exposições itinerantes como ferramenta educacional, Revista Educação, Cultura e sociedade, Sinop/MT/Brasil, v. 6, n. 1, p. 261-274.

Kuhn C.E.S., Pereira G.G., Moreira, R.M. (2016). Educação em geociências, desenvolvimento sustentável e mineração. Corixo - Revista de Extensão Universitária, v. 5, p. 44-57.

Kuhn, C.E.S., Siqueira, F.R.P.S. \& Gomes, A.C.F. (2019). Extensão universitária e desenvolvimento do pensamento crítico de estudantes de engenharia de minas e geologia. Research, Society and Development, v. 8, p. 3283730.

ONU BR. Fenômenos naturais deslocaram 19,2 milhões de pessoas em 2015, alerta escritório da ONU. Website das Organizações das Nações Unidas - ONU BR. Disponível em: $<$ https://nacoesunidas.org/fenomenos-naturais-deslocaram-192-milhoes-de-pessoas-em-2015alerta-escritorio-da-onu/ > Acessado em: 04 de maio de 2019.

Pereira A.S., Shitsuka D.M., Parreira F.J., Shitsuka R. (2018). Metodologia da pesquisa científica. [e-book]. Santa Maria. Ed. UAB/NTE/UFSM. Disponível em: https://repositorio.ufsm.br/bitstream/handle/1/15824/Lic_Computacao_MetodologiaPesquisa-Cientifica.pdf?sequence=1. Acesso em: 21 out. 2019.

Programme for International Student Assessment (PISA). Resumo de resultados nacionais do PISA 2015. Disponível em : 〈https://www.oecd.org/pisa/PISA-2015-Brazil-PRT.pdf> Acessado em: 04 de maio de 2019.

Política Nacional de Extensão Universitária (PROEX), Fórum de Pró-Reitores das Instituições Públicas de Educação Superior Brasileiras. Manaus - AM. Maio de 2012.

Reis M.A. F. dos., Carvalho C.V. de A., Carvalho J.V., Rodrigues M.A. da C., Medeiros M. A.M., Villena H.H., Oliveira F.M. de., Dornelas V.R. (2005). Sistema Multimídia Educacional para o Ensino de Geociências: uma Estratégia Atual para a Divulgação da Paleontologia no Ensino Fundamental e Médio, In: ANUÁRIO DO INSTITUTO DE GEOCIÊNCIAS, Vol. 28-1, p. 70-79. 
Ruchkys Ú.A., Machado M.M.M., Cachão M. (2012). Programa Rocha Amiga, Iniciativas para Crianças do Ensino Fundamental no Quadrilátero Ferrífero, Minas Gerais - Brasil; In: ANUÁRIO DO INSTITUTO DE GEOCIÊNCIAS. Vol. 35 - 1. p.261-270

Silva D. G. (2018). O ensino de geociências no contraturno escolar decifrando a terra possibilidades e desafios para inserção das geociências na escola. Campinas, SP : [s.n.], 2018. Dissertação de mestrado - Universidade Estadual de Campinas, Instituto de Geociências.

Vaz J. G., Carneiro V. A. (2014). Escala de Mohs: o grau de dureza dos minerais dos estojos didáticos do acervo da segep - seção de geologia e paleontologia da ueg/ccet. Revista Percurso - NEMO. Maringá, v. 8, n. 2, p. 27- 57, 2016. DOI: 10.4025/revpercurso.v8i2.31382

Universidade Federal de Mato Grosso. (2014). Engenharia de Minas, Projeto Pedagógico de Curso de Graduação 2014 A 2019. Campus Universitário Várzea Grande.

UFMT (2017, agosto 16). Projeto Educação e Geociências realiza exposições em escolas públicas. https://www.ufmt.br/ufmt/site/noticia/visualizar/37020/sinop

UFMT (2018, junho 19). Programa de extensão da UFMT expõe acervo em escola de Cuiabá. https://www.ufmt.br/ufmt/site/noticia/visualizar/41488/Cuiaba

Seduc-MT (2016, setembro 23). Escolas da rede estadual recebem exposição itinerante. http://www.mt.gov.br/-/5007120-escolas-da-rede-estadual-recebem-exposicao-itinerante

TV Universidade - UFMT (2017). Projeto de Educação em Geociência. [Arquivo de vídeo]. Recuperado de youtube.com/watch?v=mXEJ-w2trW0\&t=3s

\section{Porcentagem de contribuição de cada autor no manuscrito}

Caiubi Emanuel Souza Kuhn - 33\%

Flávia Regina Pereira Santos de Siqueira - 20\%

Livia Halle Najm de Sá - 15\%

Gustavo Gomes Pereira - 12\%

Lucas Rafael Delcico Rezende - $10 \%$ 
Research, Society and Development, v. 9, n.1, e197911861, 2020

(CC BY 4.0) | ISSN 2525-3409 | DOI: http://dx.doi.org/10.33448/rsd-v9i1.1861

Daniel Souza Dias - 10\% 